\section{HONOURS, AWARDS, APPOINTMENTS}

\begin{abstract}
Professor of Orthodontics
Martyn Cobourne has been promoted to Professor of

Orthodontics at King's College London. Professor Cobourne was appointed as a Senior Lecturer/Honorary Consultant in Orthodontics within the Dental Institute at King's College London in 2004. His current research interests focus on molecular mechanisms underlying craniofacial disorders, in particular cleft lip and palate. In addition, he has conducted several randomised controlled trials investigating clinical efficiency of orthodontic appliances.
\end{abstract}

Basic Research Prize

Dr Nikos Mardas has won the prestigious Basic Research

Prize of the European Association for Osseointegration

(EAO) for his study Novel purmorphamine/ $\beta$-TCP filled degradable polymer membrane for GBR. Dr Mardas is a Senior Clinical Lecturer in Periodontology at the UCL Eastman Dental Institute. Dr Mardas shared first prize with Dr Andreas Stavropoulos from the University of Aarhus.

\section{Double appointments for Professor Eaton}

Professor Ken Eaton has been elected as the chair of the recently formed Platform for Better Oral Health in Europe. The platform is a collaboration between the Association fo Dental Education in Europe, the Council of European Chief Dental Officers and the European Association for Dental Public Health, together with Wrigley and GlaxoSmithKline.

Professor Eaton was also elected President of the European Association of Dental Public Health (EADPH) during the recent annual meeting in Rome.

\section{Management success for 72}

A record-breaking 72 dental practice managers and dentists achieved an Institute of Leadership and Management (ILM) qualification with UMD Professional in 2011.

The successful candidates all achieved a qualification awarded by the ILM, either through attending a workshopbased course or studying via distance learning. A limited number of grants are still available for 2012.

www.umdprofessional.co.uk.

\section{First dentist on Academy council}

Professor Jonathan Shepherd of Cardiff University School of Dentistry has been elected to the Academy of Medical Sciences' council. The council is the governing body for the Academy, the independent body in the UK representing the whole spectrum of medical science.

Professor Shepherd has been a Fellow of the Academy since 2002. He becomes the first dental surgeon elected to its council and will now serve a three year term on the body.

\section{Premier Awards 2011}

The winners of the Premier Awards 2011, the annual risk management competition, were announced at the 11th Premier Symposium organised by Dental Protection and schülke. Luke Blythe and Andrew Wilson from Bristol Dental School won first prize in the undergraduate category; Anchal Puri and Gilliam Smith won first prize in the postgraduate category; and Jack Colclough, a dental hygienist, won first prize in the dental care professional (DCP) category.

\section{TONY ROWS 100 MILES}

Tony Chivers, who featured in the $B D J$ news on 12 November 2011 (page 402), has successfully completed his fundraising challenge to row 100 miles in 30 days on a Concept Rowing Machine. He took a total of 18 hours over four weeks at an average speed of $6 \mathrm{mph}$ to complete the challenge.
Tony, 91, has raised over $£ 2,500$ but still has some way to go to reach his ambitious target of $£ 10,000$ for the BDA Benevolent Fund and the Dentists' Health Support Trust.

To donate visit www.JustGiving. com/TonyChiversRow 100. The BDA Benevolent Fund has received more applications for help from dentists in 2011 than ever before.

\title{
ARE YOUR CONTACT DETAILS UP TO DATE?
}

The Government is proposing to make far-reaching changes to the NHS pension scheme which will mean that dentists pay much more for their pensions and have to work longer.

The British Dental Association (BDA) is considering whether or not to ballot members on the changes. To do this the BDA urgently needs to have up to date information on members' workplace addresses. Members will be contacted over the next few weeks explaining what is needed and how to update their details. Look out for these emails and letters and please help by completing your information urgently.

\section{DENTAL X-RAYS CAN PREDICT FRACTURE RISK}

A study reported in Nature Reviews Endocrinology states that it is now possible to use dental X-rays to predict who is at risk of fractures.

In a previous study, researchers from the University of Gothenburg's Sahlgrenska Academy and Region Västra Götaland demonstrated that a sparse bone structure in the trabecular bone in the lower jaw is linked to a greater chance of having previously had fractures in other parts of the body. The researchers have now taken this a step further with a new study, published in Bone, ${ }^{1}$ that shows that it is possible to use dental $\mathrm{X}$-rays to investigate the bone structure in the lower jaw, and so predict who is at greater risk of fractures in the future.

The study draws on data from the Prospective Population Study of Women in Gothenburg started in 1968. The study included 731 women who have been examined on several occasions since 1968 , when they were 38-60-years-old. $\mathrm{X}$-ray images of their jaw bone were analysed in 1968 and 1980 and the results related to the incidence of subsequent fractures.

For the first 12 years fractures were self-reported during followup examinations. It is only since the 1980s that it has been possible to use medical registers to identify fractures. A total of 222 fractures were identified during the whole observation period.

The study shows that the bone structure of the jaw was sparse in around $20 \%$ of the women aged 38-54 when the first examination was carried out, and that these women were at significantly greater risk of fractures.

The study also shows that the older the person, the stronger the link between sparse bone structure in the jaw and fractures in other parts of the body.

Although the study was carried out on women, the researchers believe that the link also applies for men.

1. Jonasson G, Sundh V, Ahlqwist M, Hakeberg M, Björkelund C, Lissner L. A prospective study of mandibular trabecular bone to predict fracture incidence in women: a low-cost screening tool in the dental clinic. Bone 2011; 49: 873-879. 